\title{
Crowdsourcing: a review and suggestions for future research
}

\author{
ABSTRACT \\ As academic and practitioner studies on crowdsourcing have been building up since 2006, the \\ subject itself has progressively gained in importance within the broad field of management. No \\ systematic review on the topic has so far appeared in management journals, however; and, \\ moreover, the field suffers from ambiguity in the topic's definition, which in turn led to its largely \\ unstructured evolution. We, hence, propose to investigate the existing body of knowledge on \\ crowdsourcing systematically through a penetrating review in which the strengths and weakness of \\ this literature stream are presented clearly and then future avenues of research are set out. The \\ review is based upon 121 scientific articles published between January 2006 and January 2015. \\ The review recognizes that crowdsourcing is ingrained in two mainstream disciplines within the \\ broader subject matter of innovation and management: 1) open innovation; and 2) co-creation. The \\ review, in addition, also touches upon several issues covered in other theoretical streams: \\ 3) information systems management; 4) organizational theory and design; 5) marketing; and \\ 6) strategy. \\ We have adopted a process perspective, applying the "Input-Process-Output" framework to \\ interpret research on crowdsourcing within the broad lines of: i) Input (Problem/Task); ii) Process \\ (session management; problem management; knowledge management; technology); and iii) \\ Outcome (solution/completed task; seekers' benefits; solvers' benefits). This framework provides a \\ detailed description of how the topic evolved over time, and suggestions concerning the future \\ direction of research are proposed in the form of research questions, which are valuable for both \\ academics and managers.
}




\section{INTRODUCTION}

Crowdsourcing is ingrained in research on open innovation and co-creation and is concerned with whether a wide number of individuals - the "crowd" - can take part actively in a company's innovation processes (Chui, Manyika, Bughin and Dobbs, 2012), thereby allowing the company access to intelligence and knowledge that is otherwise dispersed among a great many users or stakeholders (Chanal and Caron-Fasan, 2010; Schenk and Guittard, 2011).

In 2006, Howe coined the term crowdsourcing and defined it as "the act of a company or institution taking a function once performed by employees and outsourcing it to an undefined (and generally large) network of people in the form of an open call. This can take the form of peer-production (when the job is performed collaboratively), but is also often undertaken by sole individuals (expert or novices). The crucial prerequisite is the use of the open call and large network of potential labours" (Howe, 2006).

This definition supports the argument that crowdsourcing has its origin in research on co-creation, putting forward the suggestion that it makes sense to widen the pool of individuals who contribute towards the process of value creation (Chui, Manyika, Bughin and Dobbs, 2012; Greer and Lei, 2012). We can, in fact, say that crowdsourcing is a branch of co-creation practice, which has been made possible through the upsurge of the web, where the "crowd" can help in validating, modifying and improving a company's value-creating idea or the material it posts over the internet. The process can also apply the idea generation phase, whenever a company asks customers or other outsiders to bring their own concepts and designs to the process (Chui, Manyika, Bughin and Dobbs, 2012; Poetz and Schreier, 2012). The internet was clearly the main enabling factor for crowdsourcing, because companies were able to tap into a potentially unlimited number of people with very little effort. With the joint 
combination of the web and co-creation dynamics, this meant that the crowd was coopted as a major partner in the innovation processes taking place within companies. Crowdsourcing is also in step with the literature on open innovation: idea competitions are a core practice in open innovation (Leimeister, Huber, Bretschneider and Krcmar, 2009) and are, moreover, also listed in the literature among potential crowdsourcing initiatives (Brabham, 2009; Terwiesch and $\mathrm{Xu}, 2008)$. In addition, in current research, crowdsourcing is often mentioned explicitly as being an inbound open innovation practice where individual people are brought in to help solve a problem (e.g. Chanal and Caron-Fasan, 2010; Terwiesch and $\mathrm{Xu}, 2008)$.

While this is the case, whether crowdsourcing can actually be included among open innovation practices depends upon two key factors: i) the intrinsic nature of the problem that a company wants to solve and its complexity (Vukovic, 2009); and ii) the role assigned to the crowd (Rouse, 2010). A crowdsourcing request may involve anything that the company is in need of, ranging from the simple execution of repetitive tasks (an example of this is found on the Amazon Mechanical Turk platform) to much more complex solutions to R\&D problems, involving sourcing new ideas or introducing innovative applications for existing concepts (see the InnoCentive platform). Both these kinds of requests fall within the scope of crowdsourcing practice, although the former consists of solving small repetitive tasks without introducing any intrinsic innovative features, while the latter deals with creating new knowledge for the company. The crowd can, therefore, be involved either as the executor of ordinary tasks or as a contributor participating in the company's innovation process. Rouse (2012) has outlined the difference between the two, showing that, depending on the level and type of innovation requested from the crowd, crowdsourcing can be seen either as an open innovation practice and support tool, or merely as a new way to outsource simple tasks. 


\section{SETTING THE SCENE FOR THE REVIEW}

Research on crowdsourcing has flourished since 2006, when Howe came up with the term (see Figure 1). Due to the many possible interpretations and applications and to the concept's appeal in some quarters as a management catchword or motto, crowdsourcing has been studied by scholars and practitioners within several management and information systems disciplines (Whitla, 2012).

Figure 1 - Academic articles and proceedings on "crowdsourcing" in Scopus Social Sciences \& Humanities - cumulative

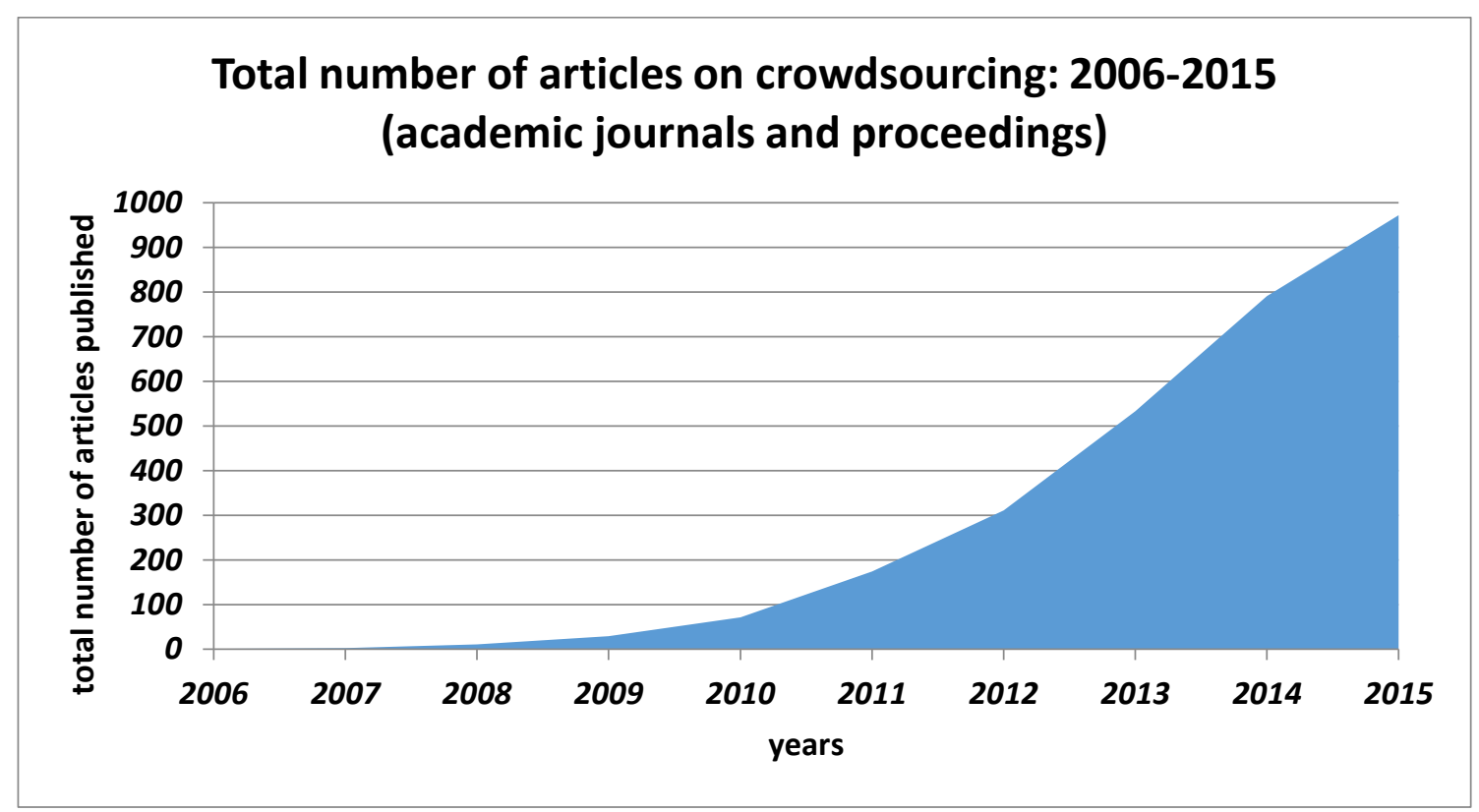

Source: SciVerse Scopus database (accessed: October $\left.1^{\text {st }}, 2015\right)$

Conceptual and empirical articles on crowdsourcing have been amassed over the past ten years, showing an exponential growth in this area. While a blanket search in Google Scholar threw up about 74,400 results, a filtered search in the SciVerse Scopus database retrieved 972 articles in the field of Social Sciences \& Humanities having 
"crowdsourcing" in their title, abstract or keywords and published in academic journals or conference proceedings from 2006 onwards (of these, 798 were published very recently, in 2012 or later).

A decade on from when crowdsourcing entered the lexicon of management, it is now evident that the research stream has proceeded along a number of paths (Geiger, Seedorf, Schulze, Nickerson and Schader, 2011; Whitla, 2012), crossing over the boundaries of innovation and technology theory where the concept had been originally conceived. However, the relatively rapid diffusion of this concept in many different directions has simultaneously meant that the relative stream of literature has expanded in an often unstructured and convoluted manner, with different scholars drawing totally opposite conclusions and sometimes departing entirely from the original definition. In existing studies, there is a generic lack of consensus on the meaning of crowdsourcing, as well as a certain semantic confusion about the word (Whitla, 2012). While it is not uncommon to find a degree of disagreement in terms of definition or concept during the phase when new ideas emerge (Gladwin, Kennelly and Krause, 1995), any lack of clarity risks undermining the development of theories in a potentially promising field and this could influence a number of management-related areas.

In the light of these considerations, the aim of this study is to conduct an extensive and systematic review of the existing body of knowledge relating to crowdsourcing, outlining the multi-faceted evolution of this research between 2006 and 2015. A review on crowdsourcing is both timely and, for several reasons, of interest to academics and practitioners in the field of management. We have built up our argument following the guidelines set out by Davis (1971) and Short (2009). Firstly, the increasing number of published studies on the subject shows that crowdsourcing has been attracting much attention, although few proceedings papers 
contain literature reviews on crowdsourcing (Pan and Blevis, 2011; Yuen, King and Leung, 2011; Pedersen, Kocsis, Tripathi, Tarrell, Weerakoon, Tahmasbi and Vreede, 2012; Wang, Nickerson and Sakamoto 2013) and, to the best of our knowledge, no review article has so far been published on this specific theme in journals on management and innovation. As an additional point, the existing reviews by and large ignore the process perspective that is typical of crowdsourcing endeavours, failing to provide a formal framework that can be used to map the literature comprehensively. This first gap is one that we intend to address in this study. Secondly, although crowdbased models originated from fairly well-established research on customer involvement (e.g., Von Hippel, 1986) and attracted the attention of scholars, currently these models have no strong semantic or theoretical foundations. More specifically, crowdsourcing is often analysed following a somewhat disjointed approach rather than being assessed from an overarching management perspective that can disclose multi-faceted implications. This gap leaves room for revising the current definitions, identifying the controversies and common patterns and highlighting the strengths and weaknesses in the research field. Citing Afuah and Tucci (2013, p. 460): "From a theory point of view, there is still much that needs to be done as far as theorizing about crowdsourcing is concerned. [...] There is plenty of room to add value to this very timely subject". Thirdly, and more interestingly, crowdsourcing as a literature stream clearly bridges traditional barriers in the management field that revolve around the interplay of several distinct principles. In this review, we found that research into crowdsourcing originated from - and, in turn, feeds into - the streams of: 1) open innovation; and 2) co-creation. However, it also (and often simultaneously) stands at the crossroad between several mainstream management disciplines. The list includes information systems management (e.g. technologies, platforms, mechanisms, algorithms); marketing (e.g. advertising and 
promotion, marketing research); organizational theory and design (e.g. influence on micro/macro design choices and behaviour, influence on management, employees and external actors' behaviour, motivation and performance); and strategy (e.g. strategic dialogue and involvement, business models). By being so positioned at the intersection of mainstream management disciplines, crowdsourcing is a "porous" concept in need of proper review and formal structure and framework.

Drawing from the broadly accepted view of innovation as a process, our proposal is to investigate crowdsourcing from an Input-Process-Output perspective. We, hence, set out the following objectives: (i) to provide a systematic review of the process of crowdsourcing; and (ii) to make suggestions for future research.

The review is structured as follows. Section 2 contains an original framework for organizing the literature, and the method employed to conduct the review is described in Section 3. The descriptive statistics and analysis of the literature's intellectual core are presented in Section 4, while, in Section 5, we will discuss the definitions and taxonomies of crowdsourcing drawn from the extant literature. Section 6 contains the main findings and maps the published body of knowledge through the lenses of our framework. Lastly, future avenues of research are set out in Section 7, with the conclusions of the study summarized in Section 8.

\section{A FRAMEWORK TO MAP THE LITERATURE}

Due to its relative novelty, there is no unified framework that can broadly encompass the different stream dealing with crowdsourcing literature. In an attempt to frame all the many multi-faceted contributions on crowdsourcing in a systemic fashion and so prevent fragmentation, we decided to take a process view of this topic. Our proposal is anchored in innovation management (which is the theoretical field at the basis of 
crowdsourcing) and innovation is in general acknowledged as a process (Keupp, Palmiè and Gassmann, 2012). The same process approach is commonly used when analyzing open innovation (e.g. Chesbrough, 2006) and co-creation (e.g. Greer and Lei, 2012), both of which, it is generally accepted, are at the origin of crowdsourcing.

In this review, the process perspective has been incorporated into an original framework with emphasis on the Input-Process-Output (I-P-O) model (McGrath, 1964). The I-P-O framework was recently used as the foundation for other studies in the field of management (e.g. Simsek, 2009), because it can help to distinguish the main antecedents, components and outcomes of the process under scrutiny. The components that make up our I-P-O crowdsourcing framework (Figure 2) have been drawn from studies on process models (e.g. Burgelman, 1983; Van de Ven, 2007; Van Oorschot, Akkermans, Sengupta and Van Wassenhove, 2013) and the resulting framework was then used to review and interpret the extant literature.

Figure 2. Input-Process-Output (I-P-O) framework for crowdsourcing 


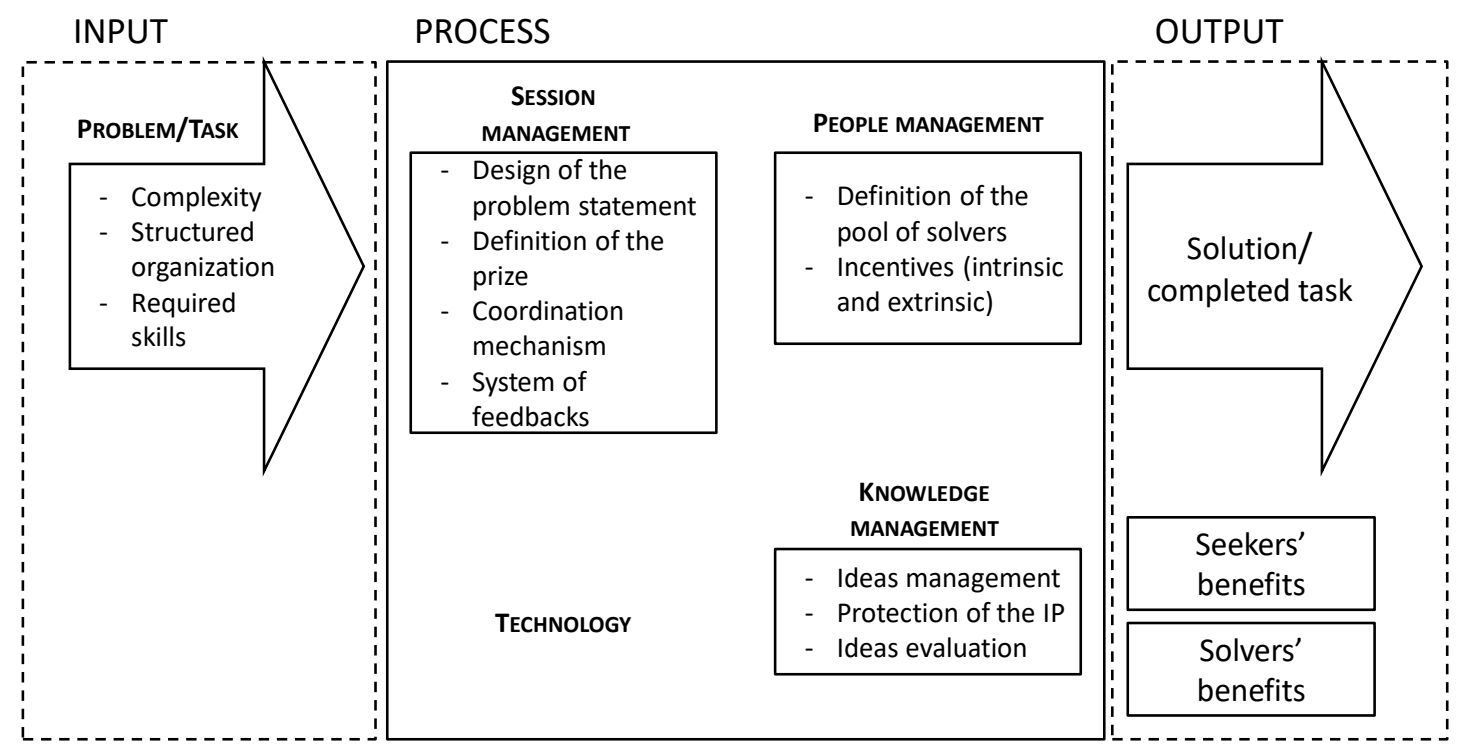

The core components of our framework are described in the following.

The main Input of crowdsourcing systems is the problem or task which has to be solved by the crowd (e.g. Geiger and Schader, 2014). Based on the typology and the

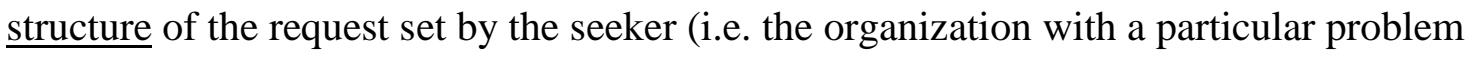
or task) and, depending on the skills required from the crowd, the crowdsourcing context will take on different features and involve different processes. Basically, it is possible to identify two kinds of requests (Boudreau and Lakhani, 2013): (i) innovationtype problems, which are well structured and generally require solvers (i.e. the crowd of active participants) with well-defined skills. Every participant is given the same problem to solve and the seeker selects a single solution or a subset of the same (e.g. InnoCentive problems); and (ii) micro-tasks, which are small tasks that do not require solvers having specific skills. The micro-tasks can be well-structured or not, and sometimes come into being when a macro-problem is broken down into more 
manageable parts. The macro-problem can then be solved by assembling all the contributions provided by the many solvers (e.g. Google Image Labeler).

Looking at the Processes involved in crowdsourcing applications, the topics concerned can be divided into the following main areas:

1. session management, covering the operations carried out by the seeker or intermediary to manage the crowdsourcing session;

2. people management, covering the strategies adopted by session managers to attract and motivate individual participants;

3. knowledge management, dealing with the organization and aggregation of the output from crowdsourcing processes, both during the session and once it has closed;

4. technologies for crowdsourcing, mostly involving studies on Information and Communication Technologies (ICT) and on software tools used by the crowdsourcing providers to manage crowdsourcing processes.

With reference to the Output of the process, there are two different kinds of solutions and/or completed tasks: (i) a solution evaluated and selected by the seeker; (ii) a microtask that is often combined with other micro-tasks to solve a larger problem (Boudreau and Lakhani, 2013). In addition to the solutions/completed tasks, we can also identify the seekers' benefits (where the seeker can be either an organization or an individual) and the solvers' benefits, seen as additional key themes within the output domain. It is worth noting that the contribution of each paper investigated, in terms of the discussion developed and conclusion reached, may simultaneously apply to more than one block in the I-P-O framework. 


\section{METHODOLOGY}

The review starts by searching the SciVerse Scopus online database for scientific articles on crowdsourcing. Since Scopus is less selective than, for example, the Web of Science (more than 23,800 titles and 5.8 million conference papers as of January 2015), this potentially means that a wider array of international outlets are searched which, in turn, could be more receptive to the emerging topic of crowdsourcing.

Moreover, because of the recent and fast growth of the literature on crowdsourcing, we decided to review papers published in both academic journals and conference proceedings. This decision came about from the consideration that, in dynamic and growing fields such as crowdsourcing, if the scope of a literature review is broadened by including publications that belong to the "grey literature" (i.e. the heterogeneous body of published material that has not been subjected to the traditional peer review process - Adams, Jeanrenaud, Bessant, Denyer and Overy, 2015), this can lead to the inclusion of novel and relevant findings and avoid the lack of immediacy determined by the lag of academic knowledge (Adams, Smart and Huff, 2016).

Since we wanted to focus on articles with management-type implications, our search was limited to the subject area of "Social Sciences and Humanities".

In line with previous reviews (e.g. Di Stefano, Peteraf and Verona, 2010; Greer and Lei, 2012), we adopted a multi-step process.

In the first step, the following first level criteria determined whether articles were included: (i) the articles were published between January 2006 and January 2015; and (ii) had to contain the term "crowdsourcing" in their title, keywords or abstract. This search resulted in over 900 articles gathered. Although the notion of "crowd" has generated other streams, we have excluded these from this review a priori. Indeed, for 
example, "crowdfunding" (where projects are funded by a large pool of contributors) is a research stream in itself (accounting for more than 250 Scopus documents).

As a second step, we retained the articles that met our more refined second level criteria: (iii) they must be relevant, as inferred from their title or abstract, or by examining the paper; (iv) they must have been published in the journals and conference proceedings of Scopus, in the sub-subject areas of management, business and decision sciences (including information systems management); and (v) they must be written in English. This phase allowed us to reduce the number of papers in the sample significantly, resulting in a working database of 121 articles.

These articles collected were then examined through a comprehensive scheme of analysis or third-level criteria, where the following were considered: title; year; author/s; publication outlet; article type (for the following labels: empirical; conceptual; literature review); related theoretical stream; research method (labels: case study; survey; conceptual-based; mathematical model; simulation; empirical test); research question/s; level of analysis of empirical studies (labels: solver; platform; seeker - single company; seeker - inter-company); definition of the crowdsourcing concept and construct; industry type; research findings; and Scopus citations. In this step, the articles were classified according to the building blocks belonging to the I-P-O framework proposed, in view of obtaining a process view on crowdsourcing.

\section{DESCRIPTIVE STATISTICS AND INTELLECTUAL CORE}

Following the method presented above, our review sheds light on the general structure and characteristics of the published body of knowledge on crowdsourcing, so as to make insightful inferences on the composition of the literature stream under scrutiny and the relative trends. Examination of the articles revealed the following findings: 
- Crowdsourcing crosses the traditional boundaries of academic disciplines, spanning from innovation management (64\% of the articles in the final database) to information systems management $(27 \%)$, organizational theory and design (7\%) and marketing and strategy (2\%);

- $23 \%$ of the articles in the sample are conceptual and are concerned with laying the foundations of a theoretical definition of the topic; $75 \%$ follow an empirical approach, where conclusions are drawn from case studies and surveys on crowdsourcing projects; the remaining $2 \%$ is made up of review papers;

- Crowdsourcing material has been dealt with, in $52 \%$ of the published articles, through qualitative methodology based on case studies; in $20 \%$ of the articles, by employing a conceptual-based methodology; in 15\%, through survey-based studies; and in $13 \%$, by other empirical methods (e.g. mathematical models, simulations).

In over half of the empirical studies (53\%), the focus is on the platform level, that is, on the intermediary system used to manage the crowdsourcing project. Only $16 \%$ of the published studies are solvers considered to be the key level of analysis, while in the remaining $31 \%$ of studies, it is the seekers that have this role. This last subset can be further split into two categories: (i) studies on a single organization, which is turning to crowdsourcing for the solution to a problem; that is, single seeking (29\%); and (ii) studies dealing with the inter-organization cases $(2 \%)$, where more than one seeker takes part in the same crowdsourcing process (often sponsored by only one of the seekers, with little or no involvement of intermediaries).

In our structured literature review, we also identified the intellectual core of crowdsourcing as a research field (McCain, 1990; Sidorova, Evangelopoulos, Valacich and Ramakrishnan, 2008). For each of the published articles considered, Scopus citation 
analysis was used to determine which articles contributed the most to the field. Our working database of articles received 1,103 Scopus citations in the timeframe between January 2006 and January 2015. The intellectual core (Di Stefano, Peteraf and Verona, 2010) was elaborated by comparing the average number of citations that refer to the articles in our working database with the number of citations for each article in the database (the average was 9.11 citations and this was then taken as the objective threshold and used to determine whether an article was to be included in the core). We found that 18 Scopus articles received more than 9 citations and this group was set as the intellectual core for crowdsourcing. These 18 articles ratcheted up a total of 985 citations, equivalent to $89.3 \%$ of the total number of Scopus citations for the entire working database.

\section{DEFINITION OF CROWDSOURCING AND TAXONOMIES}

Before analyzing the extant literature, it is worth digging deeper into the inherent meaning of crowdsourcing, with a discussion on its definition and the taxonomies used in the literature to classify crowdsourcing initiatives.

When it comes to defining the concept, most of the studies analyzed make reference to Howe’s (2006) definition of crowdsourcing. Estellés-Arolas and González-Ladrón-deGuevara (2012, p. 198) prepared a first literature review of the existing definitions and this can possibly lead to a single unifying definition: "crowdsourcing is a type of participative online activity in which an individual, an institution, a non-profit organization, or company proposes to a group of individuals of varying knowledge, heterogeneity and number, via a flexible open call, the voluntary undertaking of a task $[\ldots]^{\prime}$. 
Several crowdsourcing taxonomies are provided in the literature. The most salient classifications make reference to various different perspectives and include: the nature of the task (e.g. Pénin and Burger-Helmchen, 2011; Rouse, 2010; Lukyanenko, Parsons and Wiersma, 2014), the crowd characteristics (e.g. von Briel and Schneider 2012; Saxton, Oh and Kishore, 2010), the type of crowd knowledge (Diener and Piller, 2009), the kind of remuneration (e.g. Geiger, Seedorf, Schulze, Nickerson and Schader, 2011; Pénin and Burger-Helmchen, 2011), how far can contributors access each other's contributions (Geiger, Seedorf, Schulze, Nickerson and Schader, 2011; Diener and Piller, 2009), how closely solvers work together (Weiwei, 2012), the methods used to aggregate the contributions (Geiger, Seedorf, Schulze, Nickerson and Schader, 2011) and how the crowdsourcing process actually takes place (Chiu, Liang and Turban, 2014). The taxonomies developed are generally used to classify existing platforms (Corney, Torres-Sánchez, Jagadeesan and Regli, 2009; Geiger, Seedorf, Schulze, Nickerson and Schader, 2011; von Briel and Schneider, 2012), while some researchers have classified crowdsourcing systems from a theoretical point of view. For instance, Geiger, Rosemann, Fielt and Schader (2012) crafted a taxonomy to identify four archetypal systems on the basis of two criteria and so classify the ensuing contributions: (i) degree of homogeneity; and (ii) emergent vs. non-emergent value. Pisano and Verganti (2008) defined four kinds of collaboration based on the two features: (i) degree of openness; and (ii) network governance structure (hierarchical vs. flat). Lastly, Colombo and Buganza (2013) distinguished between two kinds of intermediary dimensions: (i) the competition architecture; and (ii) the competence searching architecture. They also tried to match intermediary architecture with the type of problem, based upon the four forms of crowdsourcing proposed by Boudreau and Lakhani (2013): (i) contest; (ii) collaborative communities; (iii) complementors; and (iv) labour market. 


\section{MAPPING THE LITERATURE THROUGH THE I-P-O FRAMEWORK}

The literature on crowdsourcing is mapped in the section below and discussed through the I-P-O framework.

\section{INPUT}

The first part of the framework concerns the kind of problems/tasks to be faced in crowdsourcing initiatives.

\section{Problem/task}

One of the main dimensions for classifying crowdsourcing projects is by kind of request. These requests generally depend upon three parameters: (i) the required knowledge for solvers to participate actively; (ii) the typology; and iii) the structure of the problem. In general terms, the task/problem should be simple, easy to delineate, well-specified and modular (Afuah and Tucci 2012; Barbier, Zafarani, Gao, Fung and Liu 2012; Sieg, Wallin and Von Krogh, 2010; Nevo, Kotlarsky and Nevo, 2012). However, according to Erickson, Petrick and Trauth (2012), two different kinds of tasks can be resolved successfully through crowdsourcing: (i) routine time-consuming tasks and (ii) nonroutine complex tasks. Rouse (2010) identified an intermediate class of problems, that of moderate tasks.

Crowdsourcing is more suited to needs-based than technology-based problems (Poetz and Schreier, 2012) and it works for innovative, expertise-based projects, but not for those of a trial-and-error variety (Terwiesch and Xu 2008). On the flip side, some studies still question whether crowdsourcing can give good results in an innovation-type problem (e.g. Schuurman, Baccarne, Marez and Mechant, 2012). 
Additionally, the extant literature highlights different types of problems/tasks or areas where crowdsourcing is particularly effective, which include the Text Retrieval Conference (TREC) relevance assessment (Alonso and Mizzarro, 2012), e-governance projects (Poblet, 2011; Alam and Campbell, 2013; Bhagwatwar and Desouza, 2012) and crisis management initiatives (Vivacqua and Borges, 2011). Chen and Liu (2012) have identified which company operations can be addressed effectively through crowdsourcing (i.e. marketing, productivity, product/service innovation and knowledge capture) and have defined the preferred features of the crowd for each; and Whitla (2009) has specifically examined how companies are adopting crowdsourcing to complete marketing-related tasks.

Moreover, since solvers need proper and thorough information about the problem if they are to understand and solve it, the tasks should not be critical nor confidential (Barbier, Zafarani, Gao, Fung and Liu 2012; Nevo, Kotlarsky and Nevo, 2012). Another important variable relating to the problem submitted is the knowledge that the crowd must have for its members to be able to solve the task. This knowledge should be codified (Pénin and Burger-Helmchen, 2011), not be too specific (Barbier, Zafarani, Gao, Fung and Liu 2012) and the seeker should not hinder this knowledge from being shared amongst the crowd (Afuah and Tucci, 2012). Conley and Tosti-Kharas (2014) have also argued, with reference to micro-tasks, that anonymous, non-expert yet selfselected crowdsourced workers are as reliable and accurate as trained researchers.

\section{PROCESS}

The second part of the framework deals with the themes of session management, knowledge management, people management and technology.

\section{Session Management}


The management of a crowdsourcing session is concerned with all the operations that the session managers have to perform in order to coordinate and orchestrate the session. Firstly, the problem statement needs to be defined. The seeker must present the solvers with a problem that is clear and which all of them are able to understand (Feller, Finnegan, Hayes and O'Reilly, 2012; Pénin and Burger-Helmchen, 2011; Sieg, Wallin and Von Krogh, 2010); if necessary, the problem must be split into simpler problems (Jain, 2010; Sieg, Wallin and Von Krogh, 2010) and, as a last point, the problem must require an answer that is non-ambiguous, easy to evaluate and to assimilate (Pénin and Burger-Helmchen, 2011). While the criteria for providing a solution should be as precise as possible, thus limiting the solution space, the problem statement should be general enough to avoid any partiality towards a particular solution path (Sieg, Wallin and Von Krogh, 2010).

The intermediaries should be involved in guiding the seeker in designing the problem statement (Feller, Finnegan, Hayes and O'Reilly, 2012; Ye, Kankanhalli and Yang, 2012), helping them to select and define the problem correctly. This process can engage the company's internal scientists, and the problem must be made clear and explicit to solvers outside the company (Sieg, Wallin and Von Krogh, 2010).

The problem statement can contain suggestions and prompts to improve the quality and creativity of the ideas to be generated by the solvers. For instance, Morris, Dontcheva and Gerber (2012) discussed how micro-task crowdsourcing platforms can be affected by positive priming, and Wang, Nickerson and Sakamoto (2013) showed how exposure to an original idea led to a decrease in fluency (the mental flow of ideas) and increase in the average originality of the ideas generated by each participant.

Another key decision that must be made is whether the initiative to be crowdsourced should be set up as a collaboration (where the participants work together to achieved a 
shared valuable outcome) or a competition/contest (were participants compete to provide the finest solution and a subset of winners are awarded a prize) (Boudreau and Lakhani, 2013). When incentives are monetary, for a contest to be set in place successfully, a pricing strategy must be formulated and tasks allocated efficiently (Singer and Mittal, 2013). In general, defining the prize is up to the seeker. Some frameworks (Singer and Mittal, 2013) and tools (Barowy, Curtsinger, Berger and McGregor, 2012; Karger, Oh and Shah, 2014) contain crowdsourcing mechanisms and automated processes for pricing and allocating tasks designed with requesters operating in complex markets.

Studies have also been carried out to investigate the optimal allocation of any prize money among the winners in contests of this kind, and these show that prize allocation can vary quite significantly and is dependent upon the contestants' level of aversion to risk (e.g. Archak and Sundararajan, 2009).

The award structure is generally fixed in crowdsourcing contests. The literature (e.g. Terwiesch and Xu, 2008; Wang, Ghose and Ipeirotis, 2012), however, indicates that any inefficiency of the innovation contest resulting from the solvers' underinvestment or low commitment can be reduced by changing the award structure of the innovation contest from a fixed-price award to a performance-contingent award.

Coordination mechanisms are useful for orchestrating the solvers' efforts, as well as for establishing trusted relationships (Alam and Campbell, 2013) based upon the shared responsibility of building an open sourcing ecosystem (Agerfalk and Fitzgerald, 2008). Crowdsourcing intermediaries should ensure that there is a significant flow of proposals and sufficient interaction between the solvers (Trompette, Chanal and Pelissier, 2008, Alam and Campbell, 2013). The session owners should encourage both co-operation and competition between the solvers, since this strategy is likely to increase the quality 
of the submissions (Hutter, Hautz, Füller, Mueller and Matzler, 2011). The members' willingness to participate depends on the policies in place concerning the platform's mission, the economic rules in play and its underlying social principles. A good way to induce involvement and engender sustainable performance is for the platform administrators to share their platform policies with the participants (Trompette, Chanal and Pelissier, 2008).

Operations linked to coordination are of significant importance in certain kinds of contests (e.g. crisis management projects) (Barbier, Zafarani, Gao, Fung and Liu 2012). Software tools can be developed to assist the intermediaries in terms of scheduling, pricing and quality control for the ideas (Barowy, Curtsinger, Berger and McGregor, 2012); in crowdsourcing crisis management projects, software tools can be used to identify any unmet requests or elaborate statistics that help to identify hidden patterns, which can be determined by contributions deriving from other organizations (Barbier, Zafarani, Gao, Fung and Liu 2012).

A crowdsourcing session facilitator can be useful for monitoring the various subject threads (Steiger, Matzler, Chatterjee and Ladstaetter-Fussenegger, 2012), for setting the project guidelines and driving the decision process (Jain, 2010). The facilitator can come with the platform or be part of the seeker company. In the latter case, the company should make sure that internal management is committed to the project (Agerfalk and Fitzgerald, 2008). It can also be the case that the authority of the project leaders arises naturally from the bottom-up as a result of the actual contribution that they make (Jain, 2010).

Rules must be clear for all the members involved, and they can also take part in making and changing such rules. The procedures for discussing and voting on important issues must also be defined (Jain, 2010). Clear project milestones must be provided, along with 
visibility with regards to inputs and elaboration on the data gathered, so as to ensure transparency and create trust (Agerfalk and Fitzgerald, 2008). The set of relational mechanisms adopted tends to be more organic and informal than in other more traditional project settings (Alam and Campbell 2013).

Finally, for session management to be effective, seekers have to develop new orchestration skills and also take on the role of "client" within the process (Nevo and Kotlarsky, 2014); they must inspire learning and creativity through feedback from professionals and experts (Kosonen, Gan, Vanhala and Blomqvist, 2014; Zhu, Djurjagina and Leker, 2014); and set futuristic contexts in which ideas can be generated (Graham and Mehmood, 2014).

\section{Knowledge Management}

Crowdsourcing initiatives enable organizations to acquire knowledge both from individual people and from other organizations. It follows that knowledge management operations are important for gathering, organizing and exploiting the knowledge acquired.

The ideas management process is crucial both during the session and after the contest has concluded. Most literature relating to this topic proposes automated tools or algorithms to improve the quality of the results. Among these are Automan (Barowy, Curtsinger, Berger and McGregor, 2012); MobileWorks (Kulkarni, Gutheim, Narula, Rolnitzky, Parikh and Hartmann, 2012); the VMW approach (Kern, Thies and Satzger, 2011); a statistical model for managing the correctness of human-based electronic services (Kern, Thies, Zirpins and Satzger, 2012); and an algorithm to detect spammers (Vuurens and de Vries, 2012).

Since crowdsourcing initiatives are generally conducted over the internet, some studies are concerned with issues such as usability and the design of ad hoc software tools; for 
instance, Riedl, Wagner, Leimeister and Krcmar (2010) have proposed a tool to visualize and analyze new user-generated ideas. Many other studies on IT tools for crowdsourcing are presented in the various streams of literature; however, these ITspecific studies are outside of the scope of this review.

Other methodologies can enhance the level of innovation within the ideas proposed, meaning that the crowdsourcing contests are more effective. These can be methods whereby techniques are used to aggregate the ideas generated, which results in them being more highly creative (Yu and Nickerson, 2011).

Solver brokerages can reinforce knowledge mobility, innovation appropriability and dynamic stability (Feller, Finnegan, Hayes and O'Reilly, 2010). In particular, the process of filtering the proposed solution is a major enabling factor to stimulate knowledge of an appropriate kind (Feller, Finnegan, Hayes and O'Reilly, 2012). The intermediaries must, therefore, be able to filter the proposals (Blohm, Riedl, Leimeister and Krcmar, 2011).

Although tools and practice for the ideas evaluation phase are crucial in open innovation contexts, several organizations have no structured approach for assessing the proposed ideas (Schulze, Indulska, Geiger and Korthaus, 2012). Idea management systems can be of assistance to companies in these instances (Schulze, Indulska, Geiger and Korthaus, 2012) and different methods for evaluating the quality of the results have been proposed (Corney, Torres-Sánchez, Jagadeesan and Regli, 2009; Blohm, Riedl, Leimeister and Krcmar, 2011). The choice of the most suitable technique can depend on the type of task (e.g. numerical analysis can be used for a crowdsourcing task where numerical results are produced, and discrete value analysis where the task requires yes or no answers). Other studies are concerned with analyzing how effective different techniques are in assessing ideas. For instance, according to Blohm, Riedl, Leimeister 
and Krcmar (2011), multi-criteria rating scales work better than prediction markets in crowdsourcing initiatives.

Various kinds of ideas assessment methods may be used when designing these competitions, and include expert assessment, peer assessment and vox populi assessment (Lampel, Jha and Bhalla, 2012). Regarding the last approach, we know that the public performs well when assessing ideas within smart cities projects (Schuurman, Baccarne, Marez and Mechant, 2012). Some studies, however, question the performance of crowdsourcing in the process of assessing ideas: while Bonabeau (2009) found that there are advantages in assessing data through crowdsourcing, other studies conclude that collective intelligence is better at generating ideas than at evaluating ideas. Ad hoc metrics can be identified to evaluate the ideas. One of the main problems of crowdsourcing systems lies in the difficulty of identifying the distinctive features of the ideas quickly and accurately, when these features are to be used later to make judgements about the proposed innovations (Westerski, Dalamagas and Iglesias, 2012). Idea assessment metrics are employed in many studies, but these are restricted to evaluating the effectiveness of the crowdsourcing contests. Westerski, Dalamagas and Iglesias (2012) have, however, proposed a taxonomy for describing the characteristics of the ideas and the metrics for evaluating them in crowdsourcing sessions. The last topic in the knowledge management area is the protection of the intellectual property $(I P)$. This is a critical and controversial issue - and one that has already been dealt with in the open innovation literature (see Harhoff, Henkel and von Hippel, 2003) - because most crowdsourcing sites set rules that protect the seekers' rights far more strenuously than those of the solvers (Massanari, 2012). Hence, IP can be a potential source of conflict (Trompette, Chanal and Pelissier, 2009).

\section{Technologies}


Several web tools can be used in crowdsourcing initiatives and include blogs, wikis and social networks (Whitla, 2009). In general terms, the intermediaries provide the seekers' companies with a web platform together with an ad hoc forum to handle the submission of proposals. Since the amount of data to process is significant, data mining techniques can be applied to the crowdsourced data (Barbier, Zafarani, Gao, Fung and Liu 2012). The seeker can make use of software tools concerned with the visualization of ideas (Riedl, Wagner, Leimeister and Krcmar, 2010) and with crowd and knowledge management (Kulkarni, Gutheim, Narula, Rolnitzky, Parikh and Hartmann, 2012; Kern, Thies and Satzger, 2011; Barowy, Curtsinger, Berger and McGregor, 2012; Vuurens and de Vries, 2012) that both improve the quality of the results and simplify the associated governance functions.

Mobile technologies allow users to make better use of their time and access the crowdsourcing platform anywhere and at any time. As a result, there has been a surge in applications for mobile phones (Liu, Lehdonvirta, Alexandrova and Nakajima, 2011; Kulkarni, Gutheim, Narula, Rolnitzky, Parikh and Hartmann, 2012; Rosen and Greve, 2012). In general, these apps are within the sphere of initiatives for smart cities (Chatzimilioudis, Konstantinidis, Laoudias and Zeinalipour-Yazti 2012), m-governance (Poblet, 2011; Garcia, Vivacqua and Tavares, 2011) and tourism (Liu, Lehdonvirta, Alexandrova and Nakajima, 2011).

\section{People Management}

Most crowdsourcing initiatives are published as an open call and thus potentially address anybody who wishes to join in. This means that a wide and knowledgeable crowd can be assembled. Sometimes, however, the pool of solvers is selected, in order to guarantee targeted, high-quality solutions. 
The determination of the pool of solvers can depend on a number of features, which include the kind of problem involved and solvers' skills (e.g. a marketing challenge requires an external and highly diverse crowd) (Erickson, Petrick and Trauth, 2012); how the participants performed in previous contests; and the current role of the participants, who may be users/solvers or potential users (Hewing, 2013). It is known that the solvers' past winning experience in crowd-rated contests is a prediction of future success in these contests (Chen and Liu, 2012; Yang, Chen and Banker, 2011), although this finding is to some extent controversial: Bayus (2012) has demonstrated that the solvers' past success is negatively related to the number of diverse ideas proposed and Hewing (2013) has stated that potential users are more useful when engaged in problem finding than in problem solving.

The number of solvers involved is another critical variable that affects the design of the pool. Adding to the number of participants leads to a downward shift in the quality of the outcomes, since solvers all tend to reduce their own personal effort because of the greater competition (Boudreau, Lacetera and Lakhani, 2011; Terwiesch and $\mathrm{Xu}, 2008$ ). It is also true that a large pool of solvers mitigates and potentially reverses any negative impact on quality, especially in high-uncertainty contests, because of what is known as the "parallel path" effect (Boudreau, Lacetera and Lakhani, 2011) and also because this can lead to more varied sets of solutions (Terwiesch and $\mathrm{Xu}, 2008$ ).

There are also several software tools that seekers can use to find their potential "dream team" of contributors on the basis of the required skills (Kulkarni, Gutheim, Narula, Rolnitzky, Parikh and Hartmann, 2012) and the right network bringing together other potential experts (Schall, Skopik and Dustdar, 2012); these tools, based on reputation mechanisms in collaboration networks, can also be used to estimate the relative importance of solvers, (Schall, 2012). 
Idea competitions draw in people encouraged by the incentives put in place or exploited by intermediaries (Leimeister, Huber, Bretschneider and Krcmar, 2009). The reasons for participating can be intrinsic, which is when an individual joins the process without any external incentives, or extrinsic, which is when external incentives come into play and can include monetary rewards or recognition (Ryan and Deci 2000). Several reasons can be behind the solvers' decision to take part in a crowdsourcing contest (see Table 1) and numerous studies are taken up with identifying them (Tokarchuk, Cuel and Zamarian, 2012; Ali Acar and van den Ende, 2011; Hossain, 2012; Rouse, 2010; Zhao and Zhu, 2014). Understanding the solvers' motivation can result in designing a better system of incentives (Leimeister, Huber, Bretschneider and Krcmar, 2009).

Although monetary rewards may seem the most tempting form of incentive, studies show that they are not the only persuasive inducement and sometimes can even be counter-productive (Huang, Singh and Srinivasan, 2012; Martinez and Walton, 2014). In crowdsourcing initiatives, intrinsic incentives are sometimes more powerful in motivating the solvers (Trompette, Chanal and Pelissier, 2009; Battistella and Nonino, 2012; Leimeister, Huber, Bretschneider and Krcmar, 2009; Zheng, Li and Hou, 2011) and can often instigate more substantial submissions (Frey, Lüthje and Haag, 2011). The way in which incentives are structured can affect the quality of the solutions substantially: in fact, when seekers increase the rewards or offer additional incentives to attract more participants, this may lead to submissions of a lower quality (Huang, Singh and Srinivasan, 2012).

In general terms, crowdsourcing platforms offer extrinsic incentives for outputs while, in some crowdsourcing challenges, there are also incentives linked to how actively people engage in the process (Majchrzak and Malhotra, 2013; Malhotra and Majchrzak, 2014). 
The incentive scheme can depend on:

- task/problem complexity (Sun, Fang and Lim, 2011; Zhao and Zhu, 2012), since the complexity of the task moderates the relationship between motivational factors and continuance intention (Sun, Fang and Lim, 2011);

- task/problem attributes (such as tacitness, analyzability, variability and variety) (Zheng, Li and Hou, 2011);

- the innovation process phase - the more tangible the results, the more the motivations used should be extrinsic (Battistella and Nonino, 2012).

A number of ways to incentivize and attract solvers have been identified in the literature. For instance, incentives may be associated to game-based contests (Thaler, Simperl and Wolger, 2012), to promoting learning mechanisms (Massanari, 2012; Kaikati and Kaikati, 2013) to posting comments on the platform (Bayus, 2010), or to designing engaging and interesting tasks/problems (Ebner, Leimeister and Krcmar, 2009; Schulze, Krug and Schader, 2012).

Trust in the hosting company can also affect the solvers intentions in terms of sharing knowledge (Ebner, Leimeister and Krcmar, 2009) and can be stimulated through technology-based support and knowledge-based support (Kosonen, Gan and Olander 2013).

Table 1. Main intrinsic and extrinsic motivations of the participants

\begin{tabular}{|c|c|c|}
\hline \multirow[t]{2}{*}{ 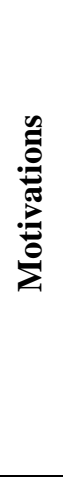 } & $\begin{array}{c}\text { Intrinsic } \\
\text { motivations }\end{array}$ & $\begin{array}{ll}- & \text { entrepreneurial mindset } \\
- & \text { opportunity to express individual creativity } \\
- & \text { caring and attachment to the group, sense of membership, ideology } \\
- & \text { enjoyment, fun and entertainment } \\
- & \text { psychological compensation and sense of efficacy } \\
- & \text { social influence and social identity } \\
- & \text { exchange of information } \\
- & \text { sense of cooperation } \\
- & \text { social search } \\
- & \text { sense of self worth } \\
- & \text { learning }\end{array}$ \\
\hline & Extrinsic & - $\quad$ monetary rewards \\
\hline
\end{tabular}




\begin{tabular}{|l|l|l|}
\hline motivations & - & reputation \\
& & - \\
& & grocognition of the company \\
& - & career benefits \\
& - & reciprocity \\
& - & accountability and social capital \\
& - & self-marketing \\
& - & social motives \\
& & \\
&
\end{tabular}

\section{OUTPUT}

The third and concluding part of our framework covers the output of a crowdsourcing initiative, concentrating on the solution/completed task and the seekers' and solvers' benefits.

\section{Solution}

The main output of a crowdsourcing initiative is generally either an innovative idea or the completion of a micro-task. On the one hand, a wide stream of literature shows that crowdsourcing processes generate users' ideas that score highly in terms of novelty and customer benefit (Poetz and Schreier 2012). According to various studies, the collaboration with users through idea competitions enhances the quality of the resulting ideas (Blohm, Bretschneider, Leimeister and Krcmar, 2011). The idea competition approach leads to good outputs even in terms of collecting data for personalization purposes (Bernstein, Tan, Smith, Czerwinski and Horvitz, 2010) and for information retrieval operations such as assessing the information's relevance (Alonso and Mizzaro, 2012).

Other studies, on the other hand, show that a generic crowdsourcing approach does not seem to be the way to generate ideas of very high quality (Rosen, 2011; Schuurman, Baccarne, Marez and Mechant, 2012), especially since the solvers' ideas are sometimes not very feasible. This means that professionals are more likely to come up with ideas 
that can be easily be developed into a market product (Huang, Singh and Srinivasan, 2011; Poetz and Schreier, 2012).

While contributors from the crowd make more inconsistent judgments compared to those of experts, the quality of the results overall increases if the results produced by the single contributors are aggregated into one output (Vuurens and de Vries, 2012).

\section{Seekers'\& Solvers'Benefits}

Several benefits can be identified for both the seekers and the solvers.

Seekers' benefits can refer to:

1. the knowledge that they have been able to acquire, or the tasks that have been performed and completed (Djelassi and Decoopman, 2013; Wang, Nickerson and Sakamoto, 2013; Huang, Singh and Srinisavan, 2011; Poetz and Schreier, 2012);

2. their relationship with a growing network of different stakeholders that are in touch with the seeker's company through the crowdsourcing undertaking (Chesbrough, 2012; Djelassi and Decoopman, 2013; Pisano and Verganti 2008; Schenk and Guittard, 2011);

3. the creation of an external "innovation and creativity" process, as an alternative to the traditional innovation processes managed internally through the company’s R\&D department (Hammon and Hippner, 2012; Trompette, Chanal and Pelissier, 2008; Pisano and Verganti, 2008; Diener and Piller, 2009).

Crowdsourcing initiatives make it possible to collect a wide range of innovative ideas (Chesbrough, 2012; Djelassi and Decoopman, 2013; Rosen, 2011; Wang, Nickerson and Sakamoto, 2013) from a large and miscellaneous crowd of solvers (Lampel, Jha and Bhalla, 2011; Wang, Nickerson and Sakamoto, 2013; Hammon and Hippner, 2012), who are then able to complete the required operations within a short time and often at a 
much reduced cost (Lampel, Jha and Bhalla, 2011; Rosen, 2011; Whitla, 2009; Ye and Kankanhalli, 2015). Another interesting debate on the issue of capturing value through crowdsourcing processes has emerged recently and is still under-investigated.

Bloodgood (2013) argues that capturing value is at a "disadvantage" in crowdsourcing undertakings because, while crowdsourcing apparently increases the leading company's ability to solve problems, this kind of problem solving seldom relates to capturing value per se, thus creating little substantive increase in performance relative to its competitors. Crowdsourcing initiatives means that companies can create or reinforce partnerships with other companies (Chesbrough, 2012; Wang, Nickerson and Sakamoto, 2013) and also galvanize their links with their customers (Djelassi and Decoopman, 2013). If the company's own employees take part in crowdsourcing contests (see Erickson, Trauth and Petrick, 2012), this can increase innovativeness within the organization and encourage a business culture in which ideas are shared (Wang, Nickerson and Sakamoto, 2013) and the process can also stimulate the level of communication between managers and their staff (Steiger, Matzler, Chatterjee and Ladstaetter-Fussenegger, 2012). It can also sometimes be the case that the crowdsourcing project is not accepted by the seeker's employees, who may even act positively against it, perceiving the initiative as an additional burden on top of their regular workload (Simula and Vuori, 2012). Another point to take into consideration is that these projects can act as a sort of recruitment tool, allowing companies to find and potentially select new people to employ (Ebner, Leimeister and Krcmar, 2009). Finally, crowdsourcing initiatives can engender improvement in brand goodwill (Wang, Nickerson and Sakamoto, 2013; Hammon and Hippner, 2012).

There are several reasons behind solvers deciding to join crowdsourcing contests. The most obvious among the benefits for solvers is a monetary reward (Djelassi and 
Decoopman, 2013; Lampel, Jha and Bhalla, 2011; Leimeister, Huber Bretschneider and Krcmar, 2009; Battistella and Nonino, 2012; Zhao and Zhu, 2012). However, it has been shown in several studies that, for these participants, money is not the only or even the main incentive. Intangible, social motives are the most important inducement and include peer appreciation and social identification (Lampel, Jha and Bhalla, 2011; Leimeister, Huber, Bretschneider and Krcmar, 2009; Battistella and Nonino, 2012; Zhao and Zhu, 2012) and self-esteem (Djelassi and Decoopman, 2013). Many people can take part in these initiatives for fun or entertainment (Djelassi and Decoopman, 2013, Battistella and Nonino, 2012). They are also aware that crowdsourcing sessions give them the potential to expand their skill base and knowledge (Lampel, Jha and Bhalla, 2011; Leimeister, Huber, Bretschneider and Krcmar, 2009). Solvers also see their participation in open source projects as a way to bring themselves to the attention of the companies involved, for the purpose of finding new job opportunities (Leimeister, Huber, Bretschneider and Krcmar, 2009).

A deeper analysis of the solvers' benefits, motivations and incentives is set out in the section on people management (see Table 1). As is apparent in our process view, crowd motivation has direct impact on the project's outcomes and is of significant concern for seekers and intermediaries. It is important for them to address the topic of incentives in order to design a contest that will attract solvers and keep them active over time.

\section{AVENUES FOR FUTURE RESEARCH ON CROWDSOURCING}

In the previous section, we reviewed the extensive literature on crowdsourcing through the I-P-O framework. While the body of knowledge dealing with crowdsourcing is massive, there are still unsolved issues requiring further research, which need to be addressed in order to increase our understanding of this phenomenon. The process of 
investigating the dynamics and mechanisms underlying crowdsourcing can also result in practical contributions, increasing the effectiveness of this approach for organizations addressing innovation and the benefits for individuals taking part in these initiatives. In the light of this consideration, we will further discuss the main matters arising from the literature review, following the I-P-O framework classification, in order to formulate suggested research questions (SRQs) to be addressed in further research.

\section{INPUT}

One of the main issues in crowdsourcing is to define the structure of the innovation problems to be broadcast to the pool of solvers. Seekers need to formulate a number of acceptable trade-offs to structure a problem effectively. Seekers must first face several types of innovation-related problems and, in all likelihood, not all of them will be solved successfully by the crowd, making it necessary to carry out an initial selection (Boudreau and Lakhani, 2013; Poetz and Schreier, 2012; Sieg, Wallin and Von Krogh, 2010; Terwiesch and Xu, 2008). Second, innovation problems often need to be reframed (especially when they are particularly complex), by, for instance, splitting them into modular stand-alone problems, making each easier for the crowd to solve (Natalicchio, Messeni Petruzzelli and Garavelli, 2014; Sieg, Wallin and Von Krogh, 2010). In this phase, the problem as formulated may no longer be strictly consistent with the starting point innovation problem, with the risk of making the crowdsourcing process less effective as a whole (Afuah and Tucci, 2012). Third, seekers must make sure that the innovation problem can be understood clearly, by providing the solvers with enough information (Afuah and Tucci, 2012), while carefully avoiding unnecessary constraints that can restrict their creativity (Sieg, Wallin and Von Krogh, 2010) and simultaneously not disclosing confidential information (Barbier, Zafarani, Gao, Fung and Liu, 2012; 
Nevo, Kotlarsky and Nevo, 2012). Finally, innovation problems should, naturally, be relevant for the seeker, but they also have to be affordable, challenging and of interest to the solvers, to ensure that solutions are submitted (Sieg, Wallin and Von Krogh, 2010). Although trade-offs of this type have a place in determining whether seekers actually make use of crowdsourcing, so far, there are no studies on investigating how to solve them concurrently. Hence, we suggest the following research question:

SRQ1: How can an innovation problem be structured so as to increase simultaneously its solvability, its intelligibility and the participation of solvers in the relative crowdsourcing session?

Alongside formulating the innovation problem, seekers using crowdsourcing to source ideas must also understand in which, among the possible fields of application, is it worthwhile resorting to the crowd. Seekers may want the crowd to solve particular innovation-type problems that relate to different application fields (e.g. Bonabeau, 2009; Chen and Liu, 2012). Crowdsourcing may be more or less effective according to the specific field of application for that problem. Poetz and Schreier (2012) found that crowd-produced solutions are valuable in the earlier idea generation phase. This is indeed consistent with crowdsourcing being employed by companies like General Electric (Chesbrough, 2012) and Dell (Bayus, 2013). Some users have a thorough knowledge of the seeker's final products and may suggest improvements or new ways in which the products can be used that can bring positive benefits to the seeker (Antorini, Muñiz and Askildsen, 2012; Von Hippel, 1986). Seekers may also find it useful to engage with solvers who have extensive knowledge in a specific domain, for help in solving specific technical problems (Garavelli, Messeni Petruzzelli, Natalicchio and 
Vanhaverbeke, 2013). Seekers make use of crowdsourcing in a variety of applications. For instance, $P \& G$ has turned to crowdsourcing both to source raw ideas and to solve specific technical issues (Huston and Sakkab, 2006). Nonetheless, there is currently no overarching understanding of the fields of application where crowdsourcing is a valuable approach to adopt, or the conditions that can help to increase the effectiveness of this method. Therefore, we pose the following research question:

SRQ2: In which fields of application and under which conditions do seekers gain the greatest advantages from using crowdsourcing?

\section{PROCESS}

In general, crowdsourcing sessions are supervised by platform managers who carry out crucial operations critical to the success of the whole process. Platform managers are responsible for selecting the innovation problem to be broadcast to the crowd and for preparing the relative statement (Feller, Finnegan, Hayes and O’Reilly, 2012; Pénin and Burger-Helmchen, 2011; Sieg, Wallin and Von Krogh, 2012). As well as defining the problem, platform managers set the award for the best solution received, a process that involves understanding and capitalizing on the reasons why solvers wish to be involved, as this increases the quality of the submissions (Frey, Lüthje and Haag, 2011; Terwiesch and $\mathrm{Xu}, 2008$; Wang, Ghose and Ipeirotis, 2012). During the session, platform managers should make sure that the intelligence of the innovation problem is spread appropriately, that solvers participate constructively and that the solvers interact in a correct manner (Alam and Campbell, 2013; Hutter, Hautz, Füller, Mueller and Matzler, 2011; Trompette, Chanal and Pelissier, 2008). Platform managers must ensure that the seekers' relationship with the solvers is fair, by establishing direct and loyal interaction 
(Gebauer, Füller and Pezzei, 2013). It may be very challenging for platform managers to control these complex activities correctly, they have to define the rules specific to the case and possess the proper skills and capabilities. While the use of governance mechanisms in crowdsourcing has been discussed in the literature (e.g. Hutter, Hautz, Füller, Mueller and Matzler, 2011; Jain, 2010), there are, so far, no studies with a focus on the individual level that examine the skills and expertise needed for platform managers to make a success of crowdsourcing for both seekers and solvers. Our third research question is, therefore, formulated as:

SRQ3: Which skills and capabilities must platform managers master to ensure the success of the crowdsourcing session?

One of the first decisions that seekers must make concerns the way in which the crowdsourcing session is structured and, specifically, whether it should take the form of a contest or a collaboration (Boudreau and Lakhani, 2013). In contests, individuals or teams work to produce the best possible solution for the seeker. Being in competition with each other means that the different solvers and/or teams of solvers tap into their own expertise and skills to develop their solutions and, consequently, develop several types of solutions (Terwiesch and $\mathrm{Xu}, 2008$ ). Due to the "parallel path" effect, it is possible to find one among the possible solutions that is extremely valuable (Boudreau, Lacetera and Lakhani, 2011). In collaborative work, on the contrary, people build on each other's skills and work to develop an idea in common (Levine and Prietula, 2014). In a collaboration, solvers disclose their ideas freely to the other members, who in turn reciprocate with their own ideas, all leading to an improved solution for the seeker (Boudreau and Lakhani, 2013). Either format can be applied successfully in practice 
(Frey, Lüthje and Hagg, 2011). There is a possible third hybrid structure where owners compete against each other in solving the problem, yet are also allowed to communicate with their peers and share ideas and insights, in order to improve the quality of the ideas submitted (Blohm, Bretschneider, Leimeister and Krcmar, 2011; Hutter, Hautz, Füller, Mueller and Matzler, 2011). Despite the critical importance of structuring a crowdsourcing session correctly, in the extant literature, little attention is spent on making a comparison between the benefits offered to the seekers by the different formats under differing conditions. We, therefore, propose the following research question:

SRQ4: In which scenarios do the different crowdsourcing session formats provide the seekers with the greatest benefits?

Seekers collect a number of ideas from the pool of solvers through crowdsourcing sessions. Knowledge management practice becomes, therefore, particularly significant in this process. One of the main sources of conflict in crowdsourcing is managing the solvers' intellectual property, IP (Trompette, Chanal and Pelissier, 2009). Since IP provided by solvers under the form of solutions is an intangible asset, crowdsourcing initiatives are affected by what is known as Arrow's information paradox (Arrow, 1962). The seeker needs to understand the solutions provided by owners clearly and in full, in order to assess accurately whether they are suitable for solving the innovation problem. This leads to the risk, however, that the seeker can misappropriate the solutions provided, without rewarding the solvers. To disentangle this paradox, it is necessary to put clear rules in place to ensure that the solvers' IP rights are managed fairly (Garavelli, Messeni Petruzzelli, Natalicchio and Vanhaverbeke, 2013). This is especially true when 
the ideas developed by the solvers are still raw and cannot be protected through mechanism such as patents (Natalicchio, Messeni Petruzzelli and Garavelli, 2014). The seekers' rights are, nevertheless, protected more under current crowdsourcing rules than those of the solvers' (Massanari, 2012). The danger in this situation is that solvers may no longer pass on their ideas to the seekers, determining a failure for that crowdsourcing session. It follows that IP management should be carefully defined by rules and policies. Accordingly, we pose the fifth research question:

SRQ5: Which rules and policies should be adopted to manage IP rights connected to the submitted solutions in a fair manner?

\section{OUTPUT}

Once the seeking organization selects the best idea from among those submitted by solvers, it should integrate that solution within its innovation processes. Several issues may emerge at this point. Externally sourced ideas can often be less feasible than those developed by professionals, since the crowd has no in-depth knowledge of the seeking organization's internal operations or cost structure (Huang, Singh and Srinisavan, 2011; 2014). In addition, the employees of the seeking organization may suffer from the "notinvented here" syndrome (Katz and Allen, 1982) and thus only use externally developed knowledge reluctantly (Lüttgens, Pollok, Antons and Piller, 2014). Seekers may not have the proper procedures to manage the transfer of IP rights effectively, with the result that there are barriers to acquiring the solvers' solutions (Garavelli, Messeni Petruzzelli, Natalicchio and Vanhaverbeke, 2013; Marjanovic, Fry and Chataway, 2012). Furthermore, seekers taking possession of external knowledge should develop a high absorptive capacity in order to assimilate externally developed ideas and exploit them (Cohen and Levinthal, 1990; Zahra and George, 2002) and this is particularly relevant 
in the case of ideas founded in knowledge domains distant from the seeker's knowledge base (Natalicchio, Messeni Petruzzelli and Garavelli, 2014). Consequently, the seeker needs to develop specific capabilities and mechanisms to integrate the selected solutions and ensure that crowdsourcing is effective. Nonetheless, there are, to the best of our knowledge, no investigations about the follow up of crowdsourcing sessions in the literature. Studies of this kind could radically increase the usefulness of crowdsourcing for organizations and we thus suggest the following research question:

SRQ6: Which capabilities and mechanisms can enhance the effective integration of the solvers' ideas within the seekers' innovative processes?

As stated in the previous sections, the outcome of a crowdsourcing session can be an idea or how to execute a micro-task, this being one part of a more complex task and performed by people in a matter of minutes (Morris, Dontcheva and Gerber, 2012). These are, generally, tasks that are difficult to be executed through computer programs, while are trivial for human beings, since they involve natural actions like drawing, coding, interpreting shapes and labelling images (Yuen, King and Leung, 2011). In this case, however, the tasks are performed by a pool of individuals, with their different skills and capabilities, who have self-selected themselves (Geiger and Schrader, 2014). Moreover, the same micro-task is often assigned to several different individuals, as the results can then be of a higher quality (Yuen, King and Leung, 2011). Seekers must then merge the many submissions for the same micro-task, as well as integrate the results of all the micro-tasks for the main initial task to be completed (Luz, Silva and Novais, 2015). This is another critical operation for obtaining valuable results from a crowdsourcing session. While the literature contains some empirical evidence on the 
techniques used in crowdsourcing platforms to aggregate the results of micro-tasks (Luz, Silva and Novais, 2015), there are no systematic studies on how this activity can be performed effectively and how one technique may be more appropriate than another in specific applications. As a consequence, we propose the seventh research question:

SRQ7: How can the friction that emerges when seekers aggregate micro-tasks accomplished by different individuals be overcome in an effective manner?

According to the extant literature, if more solvers take part in the crowdsourcing session, this is beneficial for seekers because of the "parallel path" effect (Boudreau Lacetera and Lakhani, 2011). Crowdsourcing platforms are similar to two-sided markets (Chesbrough, 2006), insomuch as increasing the number of solvers on the one side improves the value of participating for both seekers and solvers (Eisenmann, Parker and van Alstyne, 2006). It follows that it is desirable for the participation rate in crowdsourcing initiatives to be high. The motivation driving solvers to participate in crowdsourcing sessions has been discussed in previous sections and can, essentially, be split into intrinsic motivation, when an activity is performed for its own sake, and extrinsic motivation, when an activity is executed for a reward (Frey, Lüthje and Haag, 2011; Ryan and Deci, 2000). Therefore, crowdsourcing session managers should try to increase participation by exploiting the solvers' motivation. Previous studies have shown that intrinsic and extrinsic motivation may have different effects on the quality of the submitted solutions (Boudreau, Lacetera and Lakhani, 2011; Frey, Lüthje and Haag, 2011), but there has been no thorough investigation into the practices that can help to act on intrinsic and extrinsic motivation to draw in participation from specific types of solvers. Therefore, we pose the following final research question: 
SRQ8: Which practices allow seekers to draw on the solvers' intrinsic and extrinsic motivation to increase their participation in crowdsourcing sessions?

\section{CONCLUSIONS}

Over the last decade, crowdsourcing has been emerging as a satisfactory practice for use by organizations wishing to source new ideas and solutions to micro-tasks from the crowd. In parallel with the spreading of this practice among innovative organizations, scholars have been increasingly keen to investigate crowdsourcing, as shown by the number of relevant papers published since 2006. From a theoretical point of view, crowdsourcing can be seen as both an open innovation practice and a co-creation support tool. Research on crowdsourcing, especially during its early developmental phase, has been evolving along multiple theoretical fields, crossing a variety of management disciplines, even when there was no strong theoretical foundation. Nowadays, we can observe the high diffusion of crowdsourcing studies where many different perspectives are adopted, although this very characteristic of the research stream to provide many different perspectives also indicates the lack of a global and comprehensive view. The aim of this review is to provide a formal structure for the findings available in the academic literature, which, to the best of our knowledge, is still missing in the literature. We also intend to suggest avenues for further research, in order to increase our understanding of crowdsourcing.

In detail, we adopted the I-P-O framework as the perspective from which to discuss the extant literature, since the process perspective is helpful for integrating different contributions spanning over several theoretical fields. Using the I-P-O framework, we 
were also able to discuss the main antecedents, components and outcomes of the crowdsourcing process.

As a result of this discussion, we are offering an angle for interpreting the extant knowledge and directing future research, achieved by developing a set of suggested research questions. These SRQs possibly anticipate how the narrative within the crowdsourcing literature can evolve over time, to bridge the current limitations found in literature and move towards greater consistency and relevance of the findings - as the paths drawn by the research questions have their own stand-alone value, but also add to the value of the whole.

Beyond the value for research that derives from this study, platform providers and seeker companies interested in adopting crowdsourcing for their internal innovation process can also benefit from our review. In addition, the proposed framework and the discussion of the various issues can act as a checklist for use when designing internal and external innovation processes.

As all studies attempting to frame reality into a model, our work is not without limitations. Firstly, the research method employed for gathering and selecting the reviewed studies may not totally avoid any loss of information, as relevant studies might have been excluded from the sample. Basing the study on the more inclusive Scopus database, together with identifying a multi-step process that brings in different selection criteria, can possibly reduce the limitations. Secondly, the I-P-O framework may suggest that there is a linear and one-directional causal relationship between the building blocks. It is clear, however, as suggested in theories such as that of structuration, that human action changes social structures and this can lead to feedback effects. This potential weakness of the I-P-O should be carefully assessed in studies where the aim is to investigate causality relationships among the blocks. Thirdly, 
although the multi-step review methodology was rigorous, there may be some sort of "observer bias" in selecting the articles: this limitation should be attenuated by the breadth of the final database of articles reviewed. Fourthly, the deliberate choice of excluding tangential research fields (e.g. crowdfunding) and focus on the literature under scrutiny may have determined the loss of collateral information, leaving room for future extensions to this review.

In conclusion, our study contributes to management research by providing a thorough understanding of the extant research on crowdsourcing, with a specific framework to structure and integrate the findings of studies on crowdsourcing through multiple theoretical lenses. Additionally, the review of the literature also allowed us to deduce eight suggested research questions. These can potentially be the starting point for filling the gaps in knowledge in literature dealing with crowdsourcing and, as a consequence, increase our understanding of this approach more comprehensively, with the objective of strengthening the efforts made by practitioners to harness the innovation power of the crowd. 


\section{REFERENCES}

Adams, R.J., Jeanrenaud, S., Bessant, J., Denyer, D. and Overy, P. (2015). Sustainabilityoriented innovation: a systematic review. International Journal of Management Reviews, doi: 10.1111/ijmr.12068.

Adams, R.J., Smart, P. and Huff, A.F. (2016). Shades of Grey: Guidelines for Working with the Grey Literature in Systematic Reviews for Management and Organizational Studies. International Journal of Management Reviews, Vol. 00, 1-23 (2016), doi: 10.1111/ijmr.12102.

Afuah, A. and Tucci, C. L. (2012). Crowdsourcing as a solution to distant search. Academy of Management Review, 37, pp. 355-375.

Afuah, A. and Tucci, C. L. (2013). Capture and crowdsourcing. Academy of Management Review, 38, pp. 457-460.

Ågerfalk, P. J. and Fitzgerald, B. (2008). Outsourcing to an unknown workforce: exploring open source as a global sourcing strategy. MIS Quarterly, 32, pp. 385-409.

Alam, S. A. and Campbell. J. (2013). Role of relational mechanisms in crowdsourcing governance: an interpretive analysis. ACIS 2013 Proceedings.

Ali Acar, O. and van den Ende, J. (2008). Motivation, reward size and contribution in idea Crowdsourcing. Dime-Druid Academy, Winter Conference.

Alonso, O. and Mizzaro, S. (2012). Using crowdsourcing for TREC relevance assessment. Information Processing and Management, 48, pp. 1053-1066.

Antorini, Y.M., Muñiz, A.M. and Askildsen T. (2012). Collaborating with customer communities: Lessons from the Lego group, MIT Sloan Management Review. 53, pp. 7379.

Archak, N. and Sundararajan, A. (2009). Optimal design of Crowdsourcing contests. ICIS 2009 proceedings.

Arnould, E. J. (2005). Animating the big middle. Journal of Retailing, 81, pp. 89-96.

Arrow, K. (1962). Economic welfare and the allocation of resources for invention. In: Nelson, R.R. (Ed.), The rate and direction of innovative activity: Economic and social factors. Princeton University Press. Princeton, NJ, pp. 609-626.

Barbier, G., Zafarani, R., Gao, H., Fung, G. and Liu, H. (2012). Maximizing benefits from crowdsourced data. Computational and Mathematical Organization Theory, 18, pp. 257 279.

Barowy, D. W., Curtsinger, C., Berger, E. D. and McGregor, A. (2012). Automan: a platform for integrating human-based and digital computation. ACM SIGPLAN Notices, 47, pp. 639-654.

Barreto, I. (2010). Dynamic capabilities: a review of past research and an agenda for the future. Journal of Management January, 36, pp. 256-280.

Battistella, C. and Nonino, F. (2012). Open innovation web-based platforms: the impact of different forms of motivation on collaboration, Management, policy and practice, 14, $\mathrm{pp}$. $557-575$.

Bayus, B. L. (2013). Crowdsourcing new product ideas over time: an analysis of the dell ideastorm community. Management Science, 59, pp. 226-244.

Bernstein, M. S., Tan, D., Smith, G., Czerwinski M. and Horvitz, E. (2010). Personalization via friendsourcing, ACM Transactions on Computer-Human Interaction (TOCHI), 17, p. 6.

Bhagwatwar, A. and Desouza, K. (2012). Community Intelligence platforms: the case of open government, AMCIS 2012 Proceedings. 
Blohm, I., Riedl, C., Leimeister, J. M. and Krcmar, H. (2011). Idea evaluation mechanisms for collective intelligence in open innovation communities: Do traders outperform raters. Proceedings of 32nd International Conference on Information Systems, pp. 1-24.

Blohm, I., Bretschneider, U., Leimeister, J.M. and Krcmar, H. (2011). Does collaboration among participants lead to better ideas in IT-based idea competitions? An empirical investigation. International J. Networking and Virtual Organisations, 9, pp.106-122.

Bloodgood, J. (2013). Crowdsourcing: useful for problem solving, but what about value capture? Academy of Management Review, 38, pp. 455-457.

Bogers, M. (2011). The open innovation paradox: knowledge sharing and protection in RandD collaborations. European Journal of Innovation Management, 14, pp. 93 - 117.

Bonabeau, E. 2009. Decisions 2.0: the power of collective intelligence. MIT Sloan management review, 50, pp. 45-52.

Burgelman, R. A. (1983). A process model of internal corporate venturing in the diversified major firm. Administrative Science Quarterly, 223-244.

Boudreau, K. J. and Lakhani, K. R. (2013). Using the crowd as an innovation partner. Harvard Business review, 91, pp. 60-9.

Boudreau, K. J., Lacetera, N. and Lakhani, K. R. (2011). Incentives and problem uncertainty in innovation contests: An empirical analysis. Management Science, 57, pp. 843-863.

Brabham, D. C. (2009). Crowdsourcing the public participation process for planning projects. Planning Theory, 8, pp. 242-262.

Certo, T. S., Holcomb, T. R. and Holmes, R. M. (2009). IPO research in management and entrepreneurship: Moving the agenda forward. Journal of Management, 35, pp. 13401378.

Chanal, V., and Caron-Fasan, M. L. (2010). The difficulties involved in developing Business Models open to innovation communities: the case of a Crowdsourcing platform. $M @ n @$ gement, 13, pp. 318-340.

Chatzimilioudis, G., Konstantinidis, A., Laoudias, C. and Zeinalipour-Yazti, D. (2012). Crowdsourcing with Smartphones. IEEE Internet Computing, 16, pp. 36-44.

Chen, L., and Liu, D. (2012). Comparing strategies for winning expert-rated and crowd-rated Crowdsourcing contests: first findings. AMCIS 2012 Proceedings.

Chesbrough, H. (2012). GE's ecomagination challenge: an experiment in open innovation, California Management Review, 54, pp. 140-154.

Chesbrough, H. W. (2006). Open business models: How to thrive in the new innovation landscape, Boston,MA, Harvard Business School Press..

Chiu, C. M., Liang, T. P. and Turban, E. (2014). What can crowdsourcing do for decision support?. Decision Support Systems, 65, pp. 40-49.

Chui, M., Manyika, J., Bughin J. and Dobbs. R. (2012). The social economy: unlocking value and productivity through social technologies. McKinsey Global Institute.

Cohen, W.M. and Levinthal, D.A. (1990). Absorptive capacity: A new perspective on learning and innovation. Administrative Science Quarterly, 35, pp. 128-152.

Colombo, G. and Buganza, T. (2013). Crowdsourcing intermediaries and problem typologies: an explorative study. International Journal of Innovation Management, 17, pp.1-24.

Conley, C. and Tosti-Kharas, J. (2014). Crowdsourcing content analysis for managerial research. Management Decision, 52, pp. 675-688. 
Coombes, P.H. and Nicholson, J.D. (2013). Business models and their relationship with marketing: A systematic literature review. Industrial Marketing Management, 42, pp. 656-664.

Corbett, A., Covin, J. C., O'Connor, G. C and Tucci, C. L. (2013). Corporate entrepreneurship: state-of-the-art research and a future research agenda. Journal of Product Innovation Management, 30, pp. 812-820.

Corney, J. R., Torres-Sánchez, C., Jagadeesan, A. P. and Regli, W. C. (2009). Outsourcing labour to the cloud. International Journal of Innovation and Sustainable Development, $\mathbf{4}$, pp. 294-313.

Davis, M. S. (1971). That's interesting: Towards a phenomenology of sociology and a sociology of phenomenology. Philosophy of the Social Sciences, 1, pp. 309-344.

Di Stefano, G., Peteraf, M. and Verona, G. (2010). Dynamic capabilities deconstructed: a bibliographic investigation into the origins, development, and future directions of the research domain. Industrial and Corporate Change, 19, pp. 1187-1204.

Diener, K. and Piller, F. (2009). The Market for Open Innovation Increasing the efficiency and effectiveness of the innovation process. In: The RWTH Open Innovation Accelerator Survey, pp. 1-94.

Djelassi, S. and Decoopman, I. (2013). Customers' participation in product development through Crowdsourcing: Issues and implications. Industrial Marketing Management, 42, pp. 683-692.

Ebner, W., Leimeister, J. M. and Krcmar, H. (2009). Community engineering for innovations: the ideas competition as a method to nurture a virtual community for innovations. $R$ and D Management. 39, pp. 342-356.

Eisenmann, T., Parker, G. and van Alstyne, M.W. (2006). Strategies for two-sided markets. Harvard Business Review, 84, pp. 92-101. ).

Erickson, L. B., Trauth, E. M. and Petrick, I. (2012). Getting inside your employees' heads: navigating barriers to internal-crowdsourcing for product and service innovation, ICIS 2012 proceedings.

Erickson, L., Petrick, I. and Trauth, E. (2012). Hanging with the right crowd: Matching Crowdsourcing need to crowd characteristics. AMCIS 2012 Proceedings.

Estellés-Arolas, E. and González-Ladrón-de-Guevara, F. (2012). Towards an integrated Crowdsourcing definition. Journal of Information Science, 38, pp. 189-200.

Felekoglu, B., and Moultrie, J. (2013). Top Management Involvement in New Product Development: A Review and Synthesis. Journal of Product Innovation Management, 3, pp. 159-175.

Feller, J., Finnegan, P., Hayes, J. and O'Reilly, P. (2010). Leveraging 'the crowd': an exploration of how solver brokerages enhance knowledge mobility. ECIS 2010 proceedings.

Feller, J., Finnegan P., Hayes, J. and O'Reilly, P. (2012). Orchestrating' sustainable Crowdsourcing: A characterization of solver brokerages. Journal of Strategic Information Systems, 21, pp. 216-232.

Foss, N.J., Laursen, K. and Pedersen, T. (2011). Linking customer interaction and innovation: the mediating role of new organizational practices. Organization Science, 22, pp. 980 999. 
Frey, K., Lüthje, C. and Haag, S. (2011). Whom should firms attract to open innovation platforms? The role of knowledge diversity and motivation. Long Range Planning, 44, pp. 397-420.

Fuchs, C. and Schreirer, M. (2011). Customer Empowerment in New Product Development. Journal of Product Innovation Management, 28, pp.17-32.

Garavelli, A.C., Messeni Petruzzelli, A., Natalicchio, A. and Vanhaverbeke, W. (2013). Benefiting from markets for ideas - An investigation across different typologies. International Journal of Innovation Management, 17, 37 pages.

Garcia, A. B. C., Vivacqua, A. S. and Tavares, T. C. (2011). Enabling Crowd Participation in Governmental Decision-making. Journal of Universal Computer Science, 17, pp. 19311950.

Gassmann, O. and Enkel, E. (2004). Towards a theory of open innovation: three core process archetypes. $R$ and $D$ Management Conference proceedings.

Gebauer, J., Füller, J. and Pezzei, R. (2013). The dark and the bright side of co-creation: Triggers of member behavior in online innovation communities. Journal of Business Research, 66, pp. 1516-1527.

Geiger, D. and Schader, M. (2014). Personalized task recommendation in crowdsourcing information systems - Current state of the art. Decision Support Systems, 65, pp. 3-16.

Geiger, D., Rosemann, M., Fielt, E. and Schader, M. (2012). Crowdsourcing information system-definition, typology, and design. ICIS 2012 Proceedings.

Geiger, D., Seedorf, S., Schulze, T., Nickerson, R. and Schader, M. (2011). Managing the crowd: towards a taxonomy of Crowdsourcing processes. ACIS 2011 proceedings.

Gladwin, T. N., Kennelly, J. J. and Krause, T-S. (1995). Shifting paradigms for sustainable development: Implications for management theory and research. The Academy of Management Review, 20, pp. 874-907.

Graham, G., and Mehmood, R. (2014). The strategic prototype "crime-sourcing" and the science/science fiction behind it. Technological Forecasting and Social Change, 84, pp. 86-92.

Greer, C. R. and Lei, D. (2012). Collaborative innovation with customers: a review of the literature and suggestions for future research. International Journal of Management Reviews, 14, pp. 63-84.

Hammon, L. and Hippner, H. (2012). Crowdsourcing. Business and Information Systems Engineering. 4, pp. 163-166.

Harhoff, D., Henkel, J. and Von Hippel, E. (2003). Profiting from voluntary information spillovers: how users benefit by freely revealing their innovations. Research Policy. 32, pp. 1753-1769.

Hennala, L., Parjanen, S. and Uotila, T. (2011). Challenges of multi-actor involvement in the public sector front-end innovation processes: constructing an open innovation model for developing well-being services. European Journal of Innovation Management. 14, pp. 364-387.

Hewing, M. (2013). Merits of collaboration with potential and current users. In Creative Problem-Solving. International Journal of Innovation Management. 17, pp. 
Hossain, M. (2012). Users' motivation to participate in online crowdsourcing platforms. IEEE International Conference on Innovation Management and Technology Research. pp. 310-315.

Howe, J. (2006). The rise of Crowdsourcing. Wired Magazine. 14, available online at: http://www.wired.com/wired/archive/14.06/crowds_pr.html (accessed on 01 July 2013).

Huang, Y., Singh, P.V. and Srinivasan, K. (2011). Crowdsourcing "Blockbuster" ideas: a dynamic structural model of ideation. Thirty Second International Conference on Information Systems. Shanghai.

Huang, Y., Singh, P.V. and Srinivasan, K. (2014). Crowdsourcing new product ideas under consumer learning. Management Science. 60, pp. 2138-2159.

Huang,Y., Singh, P.V. and Mukhopadhyay, T. (2012). Crowdsourcing contests: a dynamic structural model of the impact of incentive structure on solution quality. Thirty International Conference on Information Systems, Orlando 2012.

Huston, L. and Sakkab, N. (2006). Connect and develop: inside Procter \& Gamble's new model for innovation. Harvard Business Review. 84, pp. 54-66.

Hutter, K., Hautz, L., Füller, J., Mueller, J. and Matzler, K. (2011). Communitition: the tension between competition and collaboration in community-based design contests. Creativity and Innovation Management. 20, pp. 3-21.

Jain, R. (2010). Investigation of governance mechanisms for crowdsourcing initiatives. AMCIS 2010 Proceedings. pp. 557.

Kaikati, A. M. and Kaikati, J. G. (2013). Doing business without exchanging money: the scale and creativity of modern barter. California Management Review. 55, pp. 46-71.

Karger, D. R., Oh, S. and Shah, D. (2014). Budget-optimal task allocation for reliable crowdsourcing systems. Operations Research. 62, pp. 1-24.

Katz, R. and Allen, T.J. (1982). Investigating the not invented here (NIH) syndrome: a look at the performance, tenure, and communication patterns of $50 \mathrm{R} \& \mathrm{D}$ project groups. $R \& D$ Management. 12, pp. 7-20.

Kern, R., Thies, H. and Satzger, G. (2011). Efficient quality management of human-based electronic services leveraging group decision making. ECIS 2011 Proceedings. Paper 112.

Kern, R., Thies, H., Zirpins, C. and Satzger, G. (2012). Dynamic and goal-based quality management for human-based electronic services. International Journal of Cooperative Information Systems. 21, pp. 3-29.

Keupp, M.M., Palmié, M. and Gassmann, O. (2012). The strategic management of innovation: a systematic review and paths for future research. International Journal of Management Reviews. 14, pp. 367-390.

Kosonen, M., Gan, C. and Olander, H. (2013). My idea is our idea! Supporting user-driven innovation activities in crowdsourcing communities. International Journal of Innovation Management. 17.

Kosonen, M., Gan, C., Vanhala, M. and Blomqvist, K. (2014). User motivation and knowledge sharing in idea crowdsourcing. International Journal of Innovation Management. 18. 
Kristensson, P., Matthing, J. and Johansson, N. (2008). Key strategies for the successful involvement of customers in the co-creation of new technology-based services. International Journal of Service Industry Management. 19, pp. 474-491.

Kulkarni, A., Gutheim, P., Narula, P., Rolnitzky, D., Parikh, T. and Hartmann, B. (2012). Mobileworks: designing for quality in a managed crowdsourcing architecture. IEEE Internet Computing. 16, pp. 28-35.

Lampel, J., Jha, P.P. and Bhalla, A. (2012). Test driving the future: how design competition are changing innovation. Academy of Management Perspectives. 26, pp. 71-85.

Laplume, A.O., Sonpar, K. and Litz, R. A. (2008). Stakeholder theory: reviewing a theory that moves us. Journal of Management. 34, pp. 1152-1189.

Leimeister, J. M., Huber, M., Bretschneider, U. and Krcmar, H. (2009). Leveraging crowdsourcing: activation-supporting components for it-based ideas competition. Journal of Management Information Systems. 26, pp. 197-224.

Levine, S.S. and Prietula, M.J. (2014). Open collaboration for innovation: principles and performance. Organization Science. 25, pp. 1414-1433.

Liu, T. X., Yang, J., Adamic, L. A. and Chen, Y. (2014). Crowdsourcing with all-pay auctions: a field experiment on Taskcn. Management Science. 60, pp. 2020-2037.

Liu, Y., Lehdonvirta, V., Alexandrova, T. and Nakajima, T. (2012). Drawing on mobile crowds via social media. Multimedia Systems. 18, pp. 53-67.

Lukyanenko, R., Parsons, J. and Wiersma, Y. F. (2014). The iq of the crowd: understanding and improving information quality in structured user-generated content. Information Systems Research. 25, pp. 669-689.

Lüttgens, D., Pollok, P., Antons, D. and Piller, F. (2014). Wisdom of the crowd and capabilities of a few: Internal success factors of crowdsourcing for innovation. Journal of Business Economics. 84, pp. 339-374.

Luz, N., Silva, N. and Novais, P. (2015). A survey of task-oriented crowdsourcing. Artificial Intelligence Review. 44, pp. 187-213.

Majchrzak, A. and Malhotra, A. (2013). Towards an information systems perspective and research agenda on crowdsourcing for innovation. The Journal of Strategic Information Systems. 22, pp. 257-268.

Malhotra, A. and Majchrzak, A. (2014). Managing crowds in innovation challenges. California Management Review. 56, pp. 103-123.

Marjanovic, S., Fry, C. and Chataway, J. (2012). Crowdsourcing based business models: In search of evidence for innovation 2.0. Science and Public Policy. 39, pp. 318-332.

Martinez, M. G. and Walton, B. (2014). The wisdom of crowds: the potential of online communities as a tool for data analysis. Technovation. 34, pp. 203-214.

Massanari, A. L. (2012). DIY design: how crowdsourcing sites are challenging traditional graphic design practice. First Monday. 17.

McCain, K. W. (1990). Mapping authors in intellectual space: a technical overview. Journal of the American Society for Information Science. 41, pp. 433-443.

McGrath, J.E. (1964). Social Psychology: A Brief Introduction. Rinehart and Winston, Holt, New York. 
Mention, A. L. (2011). Co-operation and co-opetition as open innovation practices in the service sector: which influence on innovation novelty?. Technovation. 31, pp. 44-53.

Montelisciani, G., Gabelloni, D., Tazzini, G. and Fantoni, G. (2014). Skills and wills: the keys to identify the right team in collaborative innovation platforms. Technology Analysis \& Strategic Management. 26, pp. 687-702.

Morris, R., Dontcheva, M. and Gerber, E. (2012). Priming for better performance in microtask crowdsourcing environments. IEEE Internet Computing. 16, pp. 13-19.

Natalicchio, A., Messeni Petruzzelli, A. and Garavelli, A.C. (2014). A literature review on markets for ideas: emerging characteristics and unanswered questions. Technovation. 34, pp. 65-76.

Nevo, D. and Kotlarsky, J. (2014). Primary vendor capabilities in a mediated outsourcing model: can IT service providers leverage crowdsourcing?. Decision Support Systems. 65, pp. 17-27.

Nevo, D., Kotlarsky, J. and Nevo, S. (2013). New capabilities: can IT service providers leverage crowdsourcing?. ICIS 2012 proceedings. pp. 1-18.

Pan, Y. and Blevis, E. (2011). A survey of crowdsourcing as a means of collaboration and the implications of crowdsourcing for interaction design. Collaboration technologies and systems (CTS). IEEE International Conference. pp. 397-403.

Pedersen, J., Kocsis, D., Tripathi, A., Tarrell, A., Weerakoon, A., Tahmasbi, N. and de Vreede, G. J. (2013). Conceptual foundations of crowdsourcing: a review of IS research. 46th Hawaii International Conference on System Sciences. pp. 579-588.

Pènin, J. and Burger-Helmchen, T. (2011). Crowdsourcing of inventive activities: definition and limits. International Journal of Innovation and Sustainable Development. 5, pp. 246263.

Pisano, G. P. and Verganti, R. (2008). Which kind of collaboration is right for you?. Harvard Business Review. 86, pp. 78-86.

Poblet, M. (2011). Rule of law on the go: new developments of mobile governance. Journal of Universal Computer Science. 17, pp. 498-512.

Poetz, M. K. and Schreier, M. (2012). The value of crowdsourcing: can users really compete with professionals in generating new product ideas?. Journal of Product Innovation Management. 29, pp. 245-256.

Prahalad, C. K. and Ramaswamy, V. (2000). Co-opting customer competence. Harvard Business Review. 78, pp. 79-87.

Prahalad, C. K. and Ramaswamy, V. (2004a). Co-creating unique value with customers. Strategy and Leadership. 32, pp. 4-9.

Prahalad, C. K. and Ramaswamy, V. (2004b). Co-creation experiences: the next practice in value creation. Journal of Interactive Marketing. 18, pp. 5-14.

Riedl, C., Wagner, S., Leimeister, J.M. and Krcmar, H. (2010). Exploring large collections of ideas in collaborative settings through visualization. Proceedings of 20th Annual Workshop on Information Technologies and Systems.

Rosen, P.A. (2011). Crowdsourcing lessons for organizations. Journal of Decision Systems, 20, pp. 309-324. 
Rosen, P. and Greve, R. (2012). The use of mobile devices as group wisdom support systems to support dynamic Crowdsourcing efforts. AMCIS 2012 Proceedings.

Rouse, A.C. (2010). A preliminary taxonomy of Crowdsourcing. Proceedings of the $21 \mathrm{st}$ Australasian Conference on Information Systems, pp. 1-10.

Ryan, R.M. and Deci, E.L. (2000). Intrinsic and extrinsic motivations: classic definitions and new directions. Contemporary Educational Psychology, 25, pp. 54-67.

Saxton, G.D., Oh, O. and Kishore, R. (2010). Rules of Crowdsourcing: models, issues, and systems of control. Information Systems Management, 30, pp. 2-20.

Schall, D. (2012). Expertise ranking using activity and contextual link measures. Data and Knowledge Engineering, 71, pp. 92-113.

Schall, D., Skopik, F. and Dustdar, S. (2012). Expert discovery and interactions in mixed service-oriented systems. IEEE Transaction on Services Computing, 5, pp. 233-245.

Schenk, E. and Guittard, C. (2011). Towards a characterization of Crowdsourcing practices. Journal of Innovation Economics, 7, pp. 93-107.

Schulze, T., Indulska, M., Geiger, D. and Korthaus, A. (2012). Idea assessment in open innovation: a state of practice. ECIS 2012 Proceedings.

Schulze, T., Krug, S. and Schader, M. (2012). Workers' task choice in Crowdsourcing and human computation markets. Thirty Third International Conference on Information Systems.

Schuurman, D., Baccarne, B., De Marez, L. and Mechant, P. (2012). Smart ideas for smart cities: investigating Crowdsourcing for generating and selecting ideas for ICT innovation in a city context. Journal of theoretical and applied electronic commerce research, 7 , pp. 49-62.

Short, J. (2009). The art of writing a review article. Journal of Management, 35, pp. 13121317.

Sidorova, A., Evangelopoulos, N., Valacich, J.S. and Ramakrishnan, T. (2008). Uncovering the Intellectual Core of the Information Systems Discipline. MIS Quarterly, 32, pp. 467482.

Sieg, J.H., Wallin, M.W. and Von Krogh, G. (2010). Managerial challenges in open innovation: a study of innovation intermediation in the chemical industry. $R \& D$ Management, 40, pp. 281-291.

Simsek, Z. (2009). Organizational ambidexterity: Towards a multilevel understanding. Journal of Management Studies, 46, pp. 597-624.

Simula, H. and Vuori, M. (2012). Benefits and barriers of Crowdsourcing in B2B firms: generating ideas with internal and external crowds. International Journal of Innovation Management, 16, 19 pages.

Singer, Y. and Mittal, M. (2013). Pricing mechanisms for Crowdsourcing markets. International World Wide Web Conference Committee (IW3C2).

Stieger, D., Matzler, K., Chatterjee, S. and Ladstaetter-Fussenegger, F. (2012). Corporate strategy-democratizing strategy: how Crowdsourcing can be used for strategy dialogues. California Management Review, 54, p. 44-68.

Sun, Y., Fang, Y. and Lim, K.H. (2012). Understanding sustained participation in transactional virtual communities. Decision Support Systems, 53, pp. 12-22.

Terwiesch, C. and Xu, Y. (2008). Innovation contests, open innovation, and multiagent problem solving. Management Science, 54, pp. 1529-1543.

Thaler, S., Simperl, E. and Wolger, S. (2012). An experiment in comparing humancomputation techniques, IEEE Internet Computing, 16, pp. 52-58. 
Tokarchuk, O., Cuel, R. and Zamarian, M. (2012). Analyzing crowd labor and designing incentives for humans in the loop. IEEE Internet Computing, 16, pp. 45-51.

Trompette, P., Chanal, V. and Pelissier, C. (2008). Crowdsourcing as a way to access external knowledge for innovation. 24th EGOS Colloquium.Van de Ven, A.H. (2007). Engaged scholarship: A guide for organizational and social research. New York: Oxford University Press.

Van Oorschot, K.E., Akkermans, H., Sengupta, K. and Van Wassenhove, L.N. (2013). Anatomy of a decision trap in complex new product development projects. Academy of Management Journal, 56, pp. 285-307.

Vivacqua, A.S. and Borges, M.R.S. (2012). Taking advantage of collective knowledge in emergency response systems. Journal of Network and Computer Applications, 35, pp. 189-198.

Von Briel, F. and Schneider, C. (2012). A taxonomy of web-based inbound open innovation initiatives. ACIS 2012 Proceedings.

Von Hippel, E. (1986). Lead users: a source of novel product concepts. Management Science, 32, pp. 791-805.

Vukovic, M. (2009). Crowdsourcing for Enterprises. 2009 Congress on Services - I.

Vuurens, J. and de Vries, A. (2012). Obtaining high-quality relevance judgments using Crowdsourcing. IEEE Internet Computing, 16, pp. 20-27.

Wang, J., Ghose, A. and Ipeirotis, P.G. (2012.) Bonus, disclosure, and choice: what motivates the creation of high-quality paid reviews? ICIS 2012 Proceedings.

Wang, K., Nickerson, L.V. and Sakamoto, Y. (2013). Crowdsourced idea generation: the effect of exposure to an original idea. ACIS 2013 Proceedings.

Weiwei, Y.E. (2012). Crowdsourcing for collaboration-oriented innovations. Social Science Letters, 1, p. 85.

Westerski, A., Dalamagas, T. and Iglesias, C.A. (2012). Classifying and comparing community innovation in Idea Management Systems. Decision Support Systems, 54, pp. $1316-1326$.

Whitla, P. (2009). Crowdsourcing and its application in marketing activities. Contemporary Management Research, 5, pp. 15-28.

Whitla, P. (2012). Towards an integrated Crowdsourcing definition. Journal of Information Science, 38, pp. 189-200.

Yang, Y., Chen, P. and Banker, R. (2011). Winner determination of open innovation contests in online markets. Thirty Second International Conference on Information Systems.

Ye, H.J. and Kankanhalli, A. (2015). Investigating the antecedents of organizational task crowdsourcing. Information \& Management, 52, pp. 98-110.

Ye, H., Kankanhalli, A. and Yang, Z. (2012). Knowledge brokering for open innovation: A case study of innovation intermediaries. ICIS 2012 Proceedings.

Yu, L. and Nickerson, J. (2011). Generating creative ideas through crowds: An experimental study of combination. Thirty Second International Conference on Information Systems.

Yuen, M., King, I. and Leung, K. (2011). A survey of Crowdsourcing systems. IEEE International Conference on Privacy, Security, Risk, and Trust, and IEEE International Conference on Social Computing.

Zahra, S.A. and George, G. (2002). Absorptive capacity: A review, reconceptualization, and extension. Academy of Management Review, 27, pp. 185-203.

Zhao, Y. and Zhu, Q. (2012). Exploring the motivations of participants in Crowdsourcing contest. $33^{\text {rd }}$ International Conference on Information Systems. 
Zhao, Y. and Zhu, Q. (2014). Evaluation on Crowdsourcing research: Current status and future direction. Information Systems Frontiers, 16, pp. 417-434.

Zheng, H., Li, D. and Hou, W. (2011). Task design, motivation, and participation in Crowdsourcing contests. International Journal of Electronic Commerce, 15, pp. 57-88.

Zhu, H., Djurjagina, K. and Leker, J. (2014). Innovative Behaviour Types And Their Influence On Individual Crowdsourcing Performances. International Journal of Innovation Management, 18, 18 pages. 